\title{
MEMBERSHIP APPLICATION
}

Send the completed application form to:

International Association of Law Libraries

Ann Morrison, Treasurer, IALL

Dalhousie Law School Library

6061 University Avenue

Halifax, Nova Scotia

CANADA B3H $4 \mathrm{H} 9$

Name of Applicant

(or personal representative, if this will be an institutional membership)

Name of Institution

Address

E-mail

I do not wish to subscribe to the IALL Member list serve.

Please check one:

$\square$ Personal Membership (\$60) $\quad \square$ Institutional Membership (\$95)

Please pay by Check, Bank Draft, or Credit Card. Instructions for each method are:

Check or Draft (made payable in US\$ to the International Association of Law Libraries)

I enclose a check for US\$ payable to International Association of Law Libraries

Credit Card (to be collected in US\$)

Please indicate card type: $\square$ VISA $\quad \square$ MasterCard

Credit card number

Expiration date

Total amount payable in US\$

Date $(\mathrm{mm} / \mathrm{dd} /$ year $)$ 1

Signature 


\section{CHINA: A SEA OF OPPORTUNITY}

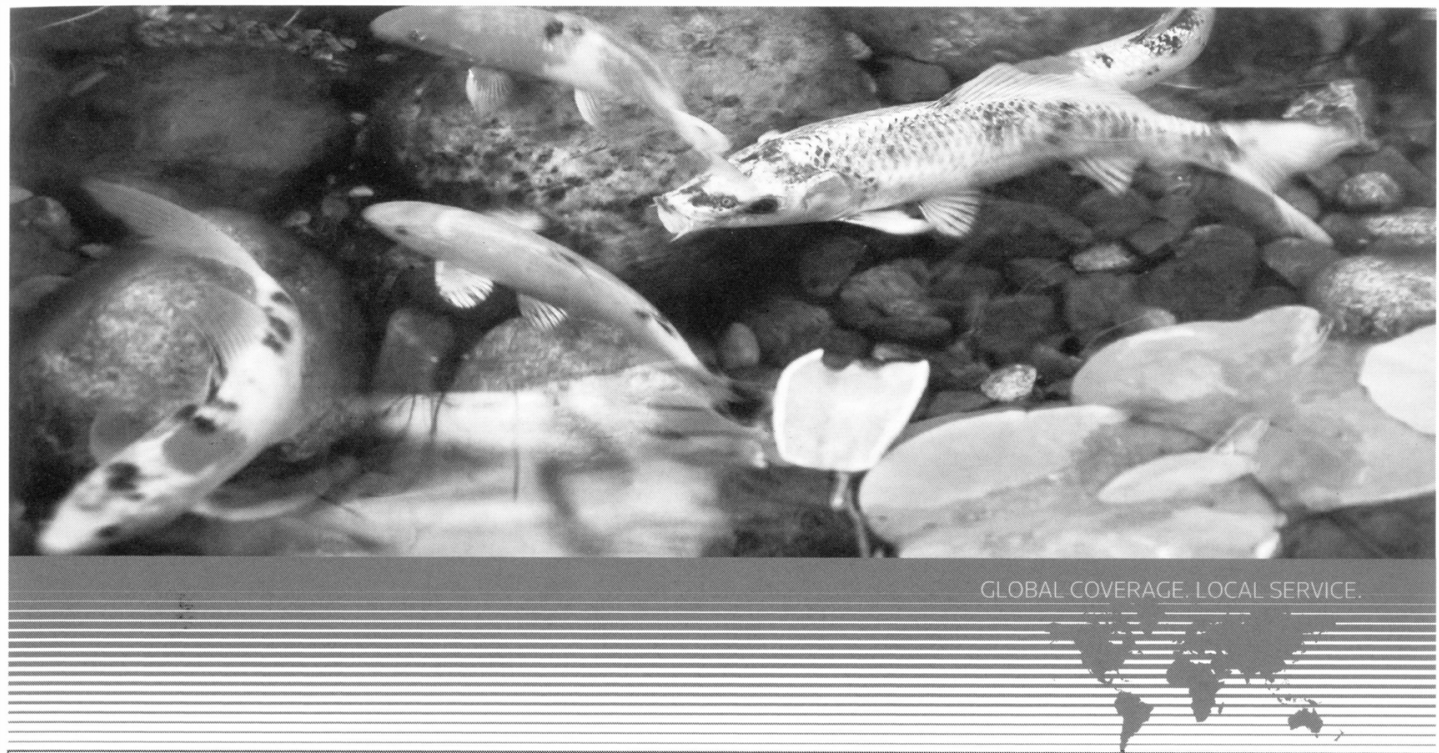

\section{Swim confidently with Westlaw China}

Now it's even easier to navigate China's legal waters

successfully. Westlaw ${ }^{\circledR}$ China not only delivers the

most current and understandable law, business

information and news from the People's Republic

of China, but also offers a powerful new online

platform and additional features for simpler, faster

and more precise research. For details and a 14-day

FREE TRIAL, call 1-800-344-5009 or visit

west.thomson.com/westlaw/global/china.

THOMSON REUTERS
Westlaw China delivers:

- More than 400,000 laws

and regulations

- Cases from the Supreme Court and provincial, local and special courts

- Digests of the law for 34 topics - eleven available in professional-quality English, with more to come

- Current Awareness Via Email, with new alerts from $120+$ online sources that keep you on top of the latest developments 
Emory University School of Law

U.S. POSTAGE

1301 Clifton Road

Atlanta, GA 30322

PAID

U.S.A.

(404) 727-6983

Fax: (404) 727-2202

Email: mengsbe@emory.edu 